International Journal of Environmental Research and

Public Health

ISSN 1660-4601

www.mdpi.com/journal/ijerph

Article

\title{
Chronic Traffic-Induced PM Exposure and Self-Reported Respiratory and Cardiovascular Health in the RHINE Tartu Cohort
}

\section{Hans Orru ${ }^{1,2, *}$, Rain Jõgi ${ }^{3}$, Marko Kaasik ${ }^{4}$ and Bertil Forsberg ${ }^{2}$}

1 Department of Public Health, University of Tartu, Ravila 19, Tartu, 50411, Estonia

2 Department of Public Health and Clinical Medicine, Umea University, Umea, SE-901 87, Sweden;

E-Mail: Bertil.Forsberg@envmed.umu.se

3 Lung Clinic, Tartu University Hospital, Riia 167, Tartu, 51014, Estonia;

E-Mail: Rain.Jogi@kliinikum.ee

4 Institute of Physics, University of Tartu, Riia 142, Tartu, 51014, Estonia;

E-Mail: Marko.Kaasik@ut.ee

* Author to whom correspondence should be addressed; E-Mail: Hans.Orru@ut.ee;

Tel.: +372-737-4203; Fax: +372-737-4191.

Received: 24 August 2009 / Accepted: 29 October 2009 / Published: 30 October 2009

\begin{abstract}
The relationship between exposure to traffic induced particles, respiratory health and cardiac diseases was studied in the RHINE Tartu cohort. A postal questionnaire with commonly used questions regarding respiratory symptoms, cardiac disease, lifestyle issues such as smoking habits, indoor environment, occupation, early life exposure and sleep disorders was sent to 2,460 adults. The annual concentrations of local traffic induced particles were modelled with an atmospheric dispersion model with traffic flow data, and obtained $\mathrm{PM}_{\text {exhaust }}$ concentrations in $40 \times 40 \mathrm{~m}$ grids were linked with home addresses with GIS. The relationship between the level of exhaust particles outside home and self-reported health problems were analyzed using a multiple logistic regression model. We found a significant relation between fine exhaust particles and cardiac disease, $O R=1.64$ (95\% CI 1.12-2.43) for increase in $\mathrm{PM}_{\text {exhaust }}$ corresponding to the fifth to the 95th percentile range. The associations also were positive but non-significant for hypertension $\mathrm{OR}=1.42$ (95\% CI 0.94-2.13), shortness of breath OR $=1.27$ (95\% CI 0.84-1.94) and other respiratory symptoms.
\end{abstract}


Keywords: air pollution; particulate matter; traffic, respiratory diseases; cardiovascular diseases

\section{Introduction}

Numerous epidemiological studies have shown an association between particulate air pollution and cardiopulmonary health [1]. Fine exhaust particles are believed to be the most harmful [2-5]. It has been assumed that traffic-induced particles emitted from combustion processes are more potent in posing adverse health effects than those from non-combustion processes. Besides exhaust emissions, the major types of traffic particles are brake wear, tyre wear, road surface abrasion and re-suspension [2]. However, meta-analysis of epidemiological studies differentiating between the coarse particles $\mathrm{PM}_{2.5-10}$ and the fine particles $\mathrm{PM}_{2.5}$, has shown that health effects exist from both fractions [3].

Traffic air pollution has been associated both with respiratory and cardiovascular effects. The cardiovascular effects of air pollution include myocardial ischemia, atherosclerosis, infarctions, heart failure, arrhythmias, strokes etc., and these are said to be the leading causes of air pollution induced morbidity and mortality [4]. Many of the studies have shown that chronic PM exposure significantly increases cardiovascular but not pulmonary mortality risk [5,6]. However, several other studies have shown that long-term PM exposure is also associated with deficiencies in lung function and increased symptoms of obstructive airway disease, such as chronic cough, bronchitis, chest illness, etc. [1]. It is possible that morbidity is more important in the context of PM exposure and respiratory health.

Some studies have associated the levels of vehicle exhaust outside the home with an increase in the incidence of asthma [7,8]. The prevalence of diagnosed asthma and asthma-like symptoms is low in Estonia, both among children [9] and adults [10], while the prevalence of non-specific respiratory symptoms [10] and bronchial hyper-responsiveness [11] is relatively high. This has raised some scepticism about the validity of doctor diagnosed asthma in Estonia [12]. However, repeated crosssectional studies in children have shown an increase in asthma prevalence in children [13] while longitudinal analysis of ECRHS cohort has shown low incidence of asthma among adults [14].

Traffic pollution has been linked with other respiratory symptoms as well. It has been associated with the prevalence of chronic bronchitis [15,16], coughing attacks, and wheezing [17] and rhinitis [18]. The links to chest tightness [19] and shortness of breath [20] are weaker or supposed.

The association between air pollution and blood pressure has also been demonstrated in several studies, but these have mostly investigated short term increases of ambient air pollutants [21]. However, some studies have found no association, particularly with long term exposure [22,23]. Nevertheless, vehicle pollution may be an important risk factor. One study reported a stronger association between $\mathrm{PM}_{2.5}$ and high blood pressure in the presence of roadway traffic [24], and Künzli et al. [24] have found association between ambient $\mathrm{PM}_{2.5}$ and atherosclerosis in an area with heavy traffic LA. A recent metaanalysis of three cross-sectional surveys found weakly positive associations between cardiovascular disease and $\mathrm{PM}_{10}$ [25].

Research into air pollution and health effects in Eastern Europe and especially in the Baltic States is limited. One reason has been the limited pollution data available, especially from earlier years. A major 
recent epidemiologic study has been conducted in Lithuania, where a relationship between exposure to urban nitrogen dioxide pollution and the risk of myocardial infarction was determined [26]. Lately a model to calculate traffic pollution concentrations in Tartu has been improved [27]. The aim of our study is to investigate the association between the prevalence of respiratory symptoms, cardiac disease and hypertension and traffic-induced particulate air pollution in the RHINE Tartu cohort in Estonia.

\section{Material and Methods}

\subsection{Study Population and Site}

In 2000/2001 a postal questionnaire was sent to 2,460 adults in Tartu that had answered the ECRHS (European Community Respiratory Health Survey, www.ecrhs.org) questionnaire sent to a random sample of people aged 25-45 in 1993. This follow up in Tartu and six other ECRHS centres established the RHINE cohort (The Respiratory Health in Northern Europe, www.rhine.nu).

Out of the invited 2,460 persons from Tartu we were able to model the $\mathrm{PM}_{\text {exposure }}$ from traffic at home for 2,216 respondents. Out of these, 1,708 persons (69\%) answered the questionnaire. Complete answers regarding respiratory health, cardiac disease, and blood pressure were obtained for 1,684 of the persons for which particle concentrations could be modelled.

The main characteristics of the study population are shown in Table 1 . The mean age of the Tartu RHINE cohort in the follow up was 35 years, they had intermediate body mass index (BMI 24.2). The prevalence of cardiac disease, and hypertension and percentage of smokers was relatively high.

Table 1. Characteristics of study population and selected prevalences.

\begin{tabular}{|c|c|c|c|c|c|c|c|c|}
\hline \multicolumn{2}{|c|}{ Age (years) } & Men & Smokers & \multicolumn{2}{c|}{ BMI } & \multicolumn{3}{c|}{ Prevalence (\%) } \\
\hline Mean & Min-max & \multicolumn{2}{|c|}{$(\%)$} & Mean & Min-max & $\begin{array}{c}\text { Cardiac } \\
\text { disease }\end{array}$ & Hypertension & $\begin{array}{c}\text { Chronic } \\
\text { bronchitis }\end{array}$ \\
\hline 35 & $25-50$ & 48 & 35.3 & 24.2 & $15.4-54.9$ & 12.4 & 12.4 & 5.7 \\
\hline
\end{tabular}

Among the rest of self-reported respiratory symptoms, the prevalence in exposed Tartu study population was highest for cough (40.5\%); but also high for wheezing (24\%), and chest tightness (16.8\%). The prevalences for the whole RHINE populations are in more detail given in Jogi et al. [10] and Toren et al. [14] papers.

Tartu is a city with 100,000 inhabitants, which makes it the second largest city in Estonia, situated in north-eastern Europe. The air pollution levels are not so high in the European context. According to ECRHS II measurements, the annual average $\mathrm{PM}_{2.5}$ concentration in Tartu during the study period was $14.8 \mu \mathrm{g} \cdot \mathrm{m}^{-3}$ [28]. According to Orru et al., [29] traffic contributes about $8 \%$ of the total $\mathrm{PM}_{2.5}$.

As the capacity of the street network remains limited despite growing traffic, congestion occurs at rush hour on several streets. A large number of cars are more than 10 years old, thus the combustion is often not of the highest standard. 


\subsection{Questionnaire on Respiratory Health and Cardiac Diseases}

From the RHINE questionnaire we concentrated on possible air pollution health effect outcomes addressed in following questions:

- Wheezing "Have you had wheezing or whistling in your chest at any time in the last 12 months?", and if so, "Have you had this wheezing or whistling when you did not have a cold?"

- Cough "Have you been woken by an attack of coughing at any time in the last 12 months?"

- Chronic bronchitis symptoms "Do you cough up phlegm in this way almost every day for at least three months every year?", and if so, "Have you had periods of this kind for at least two years in a row?"

- Non-allergic rhinitis "Have you ever experienced nasal symptoms such as nasal congestion, rhinorrhoea (runny nose) and/or sneezing attacks without having a cold?", and if "Yes"; "No" to question "Do you have any nasal allergies including hay fever?"

- Chest tightness "Have you woken up with a feeling of tightness in your chest at any time in the last 12 months?"

- Breath shortness "Have you been woken by an attack of shortness of breath at any time in the last 12 months?”

- Cardiac diseases "Do you have any cardiac disease?"

- Hypertension "Do you have high blood pressure?"

\subsection{Air Pollution Exposure}

The modelled annual mean levels of locally emitted $\mathrm{PM}_{\text {exhaust }}$ (exhaust particles) and $\mathrm{PM}_{10}$ (also road dust, tyre wear etc.) in 2000 outside the home were used as the exposure variables. The AEROPOL model that is based on Gaussian dispersion algorithm with complementary effects (e.g., reflection of Gaussian plume from the ground and capping inversion, dry and wet removal) was applied for estimating the concentrations. Simulation of long-term average PM concentrations was based on averaging the plumes over climatological distribution of thermal stratification (Pasquill-Gifford stability classes [30]), wind direction and speed. The basic concepts of AEROPOL are described by Kaasik and Kimmel [31] - these are rather similar with widely known models, e.g., ADMS [32] or AERMOD [33]. AEROPOL has been applied and validated for urban [34,35] as well as industrial [36] sources. The PM concentrations were modelled in $40 \times 40 \mathrm{~m}$ grids and geocoded addresses were linked to concentrations using the GIS software Surfer.

The average traffic flows during evening rush hour were available for 487 street links all over the city. As estimations of vehicle emission factors for Estonia are not available, the factors from other countries are used. For exhaust particles, the emission estimation methodology used by the Finnish Meteorological Institute was applied [37]. The emissions per vehicle-kilometre were calculated as was typical for Helsinki. The non-exhaust particulate matter (from road surface, tyres, brakes etc.) was estimated using the average for Stockholm, as calculated by Eneroth et al. [38]. According to their data, almost $90 \%$ of non-exhaust emissions originated from resuspension of particles from the street surface. It appears that in northern countries these emissions are roughly 10 times greater than the 
exhaust emissions because studded tyres are used. As the GDP per capita in Estonia nowadays is exceeding $70 \%$ of average level of EU and technical norms correspond completely to EU standards, the quality of the car fleet has been rapidly improved during last 10 years. Nowadays there exist no dramatic differences compared to Nordic countries, including the fact that studded tyres are in use through wintertime.

In the analysis, traffic emissions of exhaust and non-exhaust emissions together are considered as $\mathrm{PM}_{10}$ since they depend on traffic flows and show a very strong spatial correlation. However, we also present the results obtained using $\mathrm{PM}_{\text {exhaust }}$ only, since it is often assumed to be the most toxic fraction of particles due to composition or size or both [39-43].

\subsection{Statistical Analyses}

For the analysis of the relationship between PM exposure at the home address and self-reported health problems in the questionnaire, the multiple logistic regression analysis in SPSS was used. All analyses were adjusted for gender, age, body mass index (BMI), smoking history (current, ex-smoker, never) and, in the case of cardiac diseases, also for self-reported high blood pressure (yes/no).

\section{Results}

\subsection{Exposure}

The mean exposure to local traffic induced exhaust particles $\left(\mathrm{PM}_{\text {exhaust }}\right)$ was $0.10 \mu \mathrm{g} \cdot \mathrm{m}^{-3}$ and to any kind of local traffic induced particles $\left(\mathrm{PM}_{10}\right)$ was $0.76 \mu \mathrm{g} \cdot \mathrm{m}^{-3}$. Most of the streets in Tartu have low traffic flows, but some of the streets are quite busy, with elevated vehicle induced pollution levels (max of $\mathrm{PM}_{\text {exhaust }} 0.83 \mu \mathrm{g} \cdot \mathrm{m}^{-3}$ and $\mathrm{PM}_{10} 7.40 \mu \mathrm{g} \cdot \mathrm{m}^{-3}$ ) (Figure 1). As the correlation between the annual mean level of $\mathrm{PM}_{\text {exhaust }}$, and traffic related $\mathrm{PM}_{10}$ for included subjects was 0.99 and $\mathrm{PM}_{\text {exhaust }}$ is often assumed to be the most toxic, relative risks are reported only for $\mathrm{PM}_{\text {exhaust }}$.

Figure 1. Annual traffic induced $\mathrm{PM}_{\text {exhaust }}$ exposure $\left(\mu \mathrm{g} \cdot \mathrm{m}^{-3}\right)$ and prevalence of cardiac diseases in 2000 in Tartu.

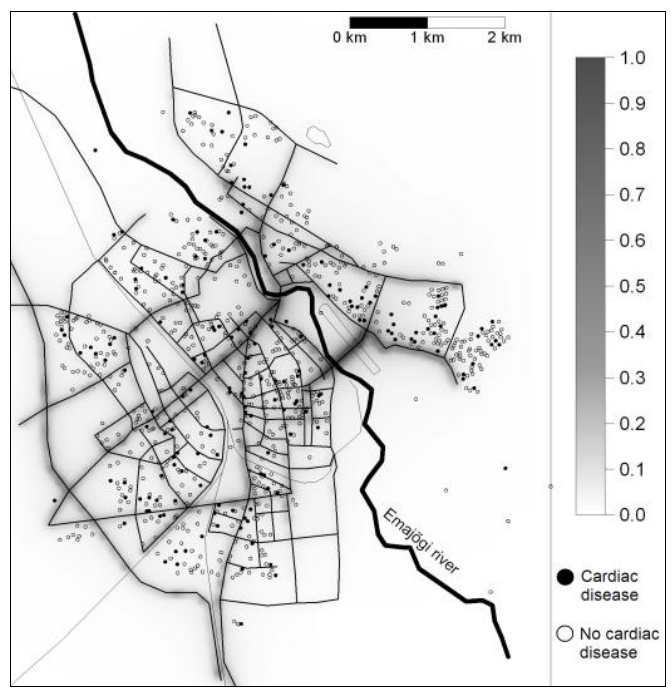




\subsection{Associations with PM at Home and Prevalences}

We found a strong correlation between concentrations of traffic-induced PM and the prevalence odds ratio (OR) for having cardiac disease, and the association became even stronger when we adjusted it for blood pressure (Table 2). For an increase in mass concentration of $1 \mu \mathrm{g} / \mathrm{m}^{3}$ the effect is as high as high $\mathrm{OR}=9.04,95 \% \mathrm{CI}=1.62-50.42$. If the $\mathrm{OR}$ for having a cardiac disease is calculated for an increase corresponding to the fifth to the $95^{\text {th }}$ percentile range, it becomes $1.64(95 \% \mathrm{CI}=1.12-2.43)$ for $\mathrm{PM}_{\text {exhaust }}$.

We did not see any significant association with respiratory symptoms (Table 2). After cardiac disease the OR was highest for hypertension and shortness of breath, problems also related to cardiovascular disease, but these associations were not significant. For people with more risky behaviour such as smokers and ex-smokers and respondents with high BMI (>25), the ORs associated with traffic PM were higher for shortness of breath, lower for cardiac diseases, and approximately the same level as the average for other outcomes.

Table 2. Relation between respiratory, and cardiac symptoms and $\mathrm{PM}_{\mathrm{exhaust}}$ exposure.

\begin{tabular}{|c|c|c|}
\hline & \multicolumn{2}{|r|}{$\mathrm{OR}^{3}\left(95 \% \mathrm{CI}^{4}\right)$} \\
\hline & $\begin{array}{c}\text { Per } 1 \mu \mathrm{g} \cdot \mathrm{m}^{-3} \text { increase in } \\
\text { exposure }\end{array}$ & $\begin{array}{c}\text { Per increase in exposure corresponding to } \\
\text { the fifth to the } 95^{\text {th }} \text { percentile }\end{array}$ \\
\hline Cough $^{1}$ & $1.01(0.28-3.64)$ & $1.00(0.75-1.34)$ \\
\hline Chronic bronchitis ${ }^{1}$ & $0.78(0.53-11.44)$ & $0.95(0.87-1.73)$ \\
\hline Non-allergic rhinitis ${ }^{1}$ & $1.79(0.45-7.17)$ & $1.14(0.83-1.56)$ \\
\hline Wheezing $^{1}$ & $1.99(0.36-11.83)$ & $1.17(0.79-1.75)$ \\
\hline Chest tightness ${ }^{1}$ & $2.34(0.48-11.48)$ & $1.21(0.85-1.74)$ \\
\hline Shortness of breath ${ }^{1}$ & $2.92(0.46-18.65)$ & $1.27(0.84-1.94)$ \\
\hline Cardiac diseases $^{1}$ & $7.56(1.40-40.68)$ & $1.58(1.08-2.31)$ \\
\hline Cardiac diseases $^{2}$ & $9.04(1.62-50.42)$ & $1.64(1.12-2.43)$ \\
\hline Hypertension $^{1}$ & $4.65(0.76-28.41)$ & $1.42(0.94-2.13)$ \\
\hline
\end{tabular}

${ }^{1}$ Logistic regression model was adjusted for gender, age, body mass index (BMI), and smoking.

${ }^{2}$ Logistic regression model was also adjusted for high blood pressure.

${ }^{3}$ Odds ratio (OR)

${ }^{4}$ Confidence interval (CI)

\section{Discussion}

Since the annual mean levels of vehicle exhaust components and road dust show a high spatial correlation due to a common source, it is not possible to study their unique influence on health within one city. Thus we see our study as an investigation of how traffic related pollution may influence health. We had much better data to model exposure levels in 2000 than for the 1993 ECRHS survey, which is why prevalence at follow up was chosen as the outcome. However, a planned future follow up within 
the next few years will make it possible to study incidence in relation to pollution levels from 2000 and later.

While the specificity and sensitivity of self-reported asthma and asthma symptoms have been studied a lot [44], we know less about validity of the questions on cardiac diseases and hypertension that were used in the RHINE study. The question used on cardiac diseases has not been validated against medical records, but other similar self-reported conditions have in different ways, at least indirectly. For example "nonspecific" chest pain has been associated with high long-term mortality in a Swedish study [45], and men who recalled a doctor diagnosis of ischemic heart disease, were at extremely high risk of a new major ischemic heart disease event during a follow-up period [46]. Moreover, there are a number of studies where myocardial infarction, angina etc have been studied using questions [47-50] that are rather similar to our questions.

It is somewhat difficult to compare our findings regarding cardiac diseases and traffic-induced particles with other studies, since more specific endpoints like myocardial infarction, arrhythmias, atherosclerosis and ischemic events usually are studied, and the true effect may be different. There are large differences in exposure assessment as well. Rosenlund et al. [51] reported ORs in Stockholm County for myocardial infarction and traffic pollution of 1.04 (95\% CI $=1.00-1.09)$ for all cases and $1.16(95 \% \mathrm{CI}=1.09-1.24)$ for fatal cases for an increase in $\mathrm{PM}_{10}$ exposure corresponding to the fifth to the 95th percentile. These are slightly lower when compared to our ORs for prevalent cardiac disease, but our Tartu estimates are for a very specific source of pollution. The same reason, and also the fact that the OR was calculated per intertertile change in $\mathrm{NO}_{2}$ exposure, could explain the lower ORs in a Lithuanian study [26]. On the other hand, Hoffmann et al. [52] indicated that people living within $50 \mathrm{~m}$ of major roads have an OR for coronary atherosclerosis through calcification as high as 1.63 $(95 \% \mathrm{CI}=1.14-2.33)$.

When we adjusted our model for cardiac diseases to also include high blood pressure, the OR increased around $10 \%$ (Table 2). However, the positive association between air pollution and high blood pressure was not significant. The reason for this might be that high pressure is usually found to be related mainly to short-term increases in exposure [21]. There are probably other trails than hypertension through what cardiac diseases are developed in the presence of traffic-induced air pollution. Inflammation through pro-oxidative, and pro-inflammatory mediators, interaction of nanoscale particles with cardiovascular systems and autonomic mechanisms in the nervous system are believed to be the main pathways [4]. Moreover, the correlation between hypertension and cardiac diseases is low in our data.

We believe there might be confounders, such as noise and stress, for which the effects are difficult to separate from the effects of air pollution. Noise, including traffic noise, has been associated with stress, sleep disturbance, blood pressure and cardiac diseases [53]. Noise may confound or modify the relation between traffic pollution and cardiac diseases as both are linked to cardiovascular effects [54]. Recent finding have found moderate correlations between traffic-generated air pollution and noise [55], but the published data are limited and somewhat inconsistent. As we had no data regarding traffic noise, we could not adjust for it. Possible confounders also are socioeconomic status, and physical activity for which we had no data. As we have adjusted for BMI and smoking history, these parameters could be indirectly included in the adjustment. 
We did not determine any significant associations with respiratory symptoms. However several studies have found such [15-20]. There might be several reasons for our null findings; selection (or survivor) bias could be one. Most people are probably aware that air pollution has a negative effect on asthma and other respiratory diseases. This may cause a selection bias in an epidemiological studypeople with respiratory problems may tend to move from polluted streets to less trafficked areas, when more healthy do not. For cardiac diseases the association with air pollution has been observed more recently by researchers and is less known to the general public. The risk of having a selection of people with cardiac diseases away from polluted areas is smaller.

The socioeconomic status may also have influenced the results. There tends to be more cardiac diseases in regions with big block houses compared to regions with residential or small apartment houses. However, the two last groups are very small and no significant difference in regression analysis appeared. These people could have been more stressed etc, what is also important factors inducing cardiac diseases.

\section{Conclusions}

In this study in Tartu a strong relation between exhaust traffic particles and cardiac diseases was established. Per $1 \mu \mathrm{g} \cdot \mathrm{m}^{-3}$ increase in exposure, the exhaust particles due to lower concentrations give much higher ORs compared to $\mathrm{PM}_{10}$ from traffic. Per change corresponding to the fifth to the 95th percentile range in exposure, there was a very small difference. We could not see any significant relation to respiratory symptoms or hypertension.

It seems that for local traffic pollution the associations here are much stronger with cardiovascular disease compared to respiratory outcomes. Even if vehicle exhaust particles are a proposed candidate to have more toxic effects, we cannot exclude other components in PM due to the high correlations. Traffic pollution is correlated with noise, which could be an important confounder.

\section{Acknowledgements}

We acknowledge all the co-workers in RHINE team, especially supporting staff in Estonia. The air pollution modeling was carried out under the auspices of the Estonian National Targeted Financing Project SF0180038s08 "Development of the Numerical Weather Prediction Towards the Forecasting of Atmospheric Environment”.

\section{References}

1. Pope, C.; Dockery, D. Health effects of fine particulate air pollution: lines that connect. J. Air Waste Manage Assoc. 2006, 56, 709-742.

2. Thorpe, A.; Harrison, R.M. Sources and properties of non-exhaust particulate matter from road traffic: A review. Sci. Total Environ. 2008, 400, 270-282.

3. Brunekreef, B.; Forsberg, B. Epidemiological evidence of effects of coarse airborne particles on health. Eur. Resp. J. 2005, 26, 309-318. 
4. Brook, R.D. Cardiovascular effects of air pollution. Clin. Sci. 2008, 115, 175-187.

5. Laden, F.; Schwartz, J.; Speizer, F.E.; Dockery, D.W. Reduction in fine particulate air pollution and mortality - Extended follow-up of the Harvard six cities study. Am. J. Respir. Crit. Care Med. 2006, 173, 667-672.

6. Pope, C.A.; Burnett, R.T.; Thurston, G.D.; Thun, M.J.; Calle, E.E.; Krewski, D.; Godleski, J.J. Cardiovascular mortality and long-term exposure to particulate air pollution-Epidemiological evidence of general pathophysiological pathways of disease. Circulation 2004, 109, 71-77.

7. Jacquemin, B.; Sunyer, J.; Forsberg, B.; Aguilera, I.; Briggs, D.; Garcia-Esteban, R.; Gotschi, T.; Heinrich, J.; Jarvholm, B.; Jarvis, D.; Vienneau, D.; Kunzli, N. Home outdoor $\mathrm{NO}_{2}$ and new onset of self-reported asthma in adults. Epidemiology 2009, 20, 119-126.

8. Modig, L.; Toren, K.; Janson, C.; Jarvholm, B.; Forsberg, B. Vehicle exhaust outside the home and onset of asthma among adults. Eur. Respir. J. 2009, 33, 1261-1267.

9. Riikjarv, M.A.; Annus, T.; Braback, L.; Rahu, K.; Bjorksten, B. Similar prevalence of respiratory symptoms and atopy in Estonian schoolchildren with changing lifestyle over 4 yrs. Eur. Resp. J. 2000, 16, 86-90.

10. Jogi, R.; Janson, C.; Bjornsson, E.; Boman, G.; Bjorksten, B. The prevalence of asthmatic respiratory symptoms among adults in Estonian and Swedish university cities. Allergy 1996, 51, 331-336.

11. Vasar, M.; Braback, L.; Julge, K.; Knutsson, A.; Riikjarv, M.A.; Bjorksten, B. Prevalence of bronchial hyperreactivity as determined by several methods among Estonian schoolchildren. Pediatr. Allergy Immunol. 1996, 7, 141-146.

12. Pallasaho, P.; Meren, M.; Raukas-Kivioja, A.; Ronmark, E. Different labelling of obstructive airway diseases in Estonia, Finland, and Sweden. Eur. J. Epidemiol. 2005, 20, 975-983.

13. Annus, T.; Riikjarv, M.A.; Rahu, K.; Bjorksten, B. Modest increase in seasonal allergic rhinitis and eczema over 8 years among Estonian schoolchildren, In 8th Congress of the Asia-PacificAssociation-of-Pediatric-Allergy-Respirology-and-Immunology, Seoul, South Korea, 2004, 2005; Blackwell Publishing: Seoul, South Korea, 2005; pp. 315-320.

14. Toren, K.; Gislason, T.; Omenaas, E.; Jogi, R.; Forsberg, B.; Nystrom, L.; Olin, A.C.; Svanes, C.; Janson, C.; RHINE Group. A prospective study of asthma incidence and its predictors: the RHINE study. Eur. Resp. J. 2004, 24, 942-946.

15. Lindgren, A.; Stroh, E.; Montnémery, P.; Nihlén, U.; Jakobsson, K.; Axmon, A. Traffic-related air pollution associated with prevalence of asthma and COPD/chronic bronchitis. A cross-sectional study in Southern Sweden. Int. J. Health Geogr. 2009, 8, 2.

16. Sunyer, J.; Jarvis, D.; Gotschi, T.; Garcia-Esteban, R.; Jacquemin, B.; Aguilera, I.; Ackerman, U.; de Marco, R.; Forsberg, B.; Gislason, T.; Heinrich, J.; Norback, D.; Villani, S.; Kunzli, N. Chronic bronchitis and urban air pollution in an international study. Occup. Environ. Med. 2006, 63, 836-843.

17. Heinrich, J.; Topp, R.; Gehring, U.; Thefeld, W. Traffic at residential address, respiratory health, and atopy in adults: the National German Health Survey 1998. Environ. Res. 2005, 98, 240-249. 
18. Cesaroni, G.; Badaloni, C.; Porta, D.; Forastiere, F.; Perucci, C.A. Comparison between various indices of exposure to traffic-related air pollution and their impact on respiratory health in adults. Occup. Environ. Med. 2008, 65, 683-690.

19. Ko, F.W.S.; Lai, C.K.W.; Woo, J.; Ho, S.C.; Ho, C.W.M.; Goggins, W.; Hui, D.S.C. 12-year change in prevalence of respiratory symptoms in elderly Chinese living in Hong Kong. Resp. Med. 2006, 100, 1598-1607.

20. Goldberg, M.S.; Giannetti, N.; Burnett, R.T.; Mayo, N.E.; Valois, M.-F.; Brophy, J.M. Shortness of breath at night and health status in congestive heart failure: Effects of environmental conditions and health-related and dietary factors. Environ. Res. 2009, 109, 166-174.

21. Dvonch, J.T.; Kannan, S.; Schulz, A.J.; Keeler, G.J.; Mentz, G.; House, J.; Benjamin, A.; Max, P.; Bard, R.L.; Brook, R.D. Acute effects of ambient particulate matter on blood pressure. Differential effects across urban communities. Hypertension 2009, 53, 853-859.

22. Lipfert, F.W.; Perry, H.M.; Miller, J.P.; Baty, J.D.; Wyzga, R.E.; Carmody, S.E. Air pollution, blood pressure, and their long-term associations with mortality. Inhal. Toxicol. 2003, 15, 493-512.

23. Madsen, C.; Nafstad, P. Associations between environmental exposure and blood pressure among participants in the Oslo Health Study (HUBRO). Eur. J. Epidemiol. 2006, 21, 485-491.

24. Kunzli, N.; Jerrett, M.; Mack, W.J.; Beckerman, B.; LaBree, L.; Gilliland, F.; Thomas, D.; Peters, J.; Hodis, H.N. Ambient air pollution and atherosclerosis in Los Angeles. Environ. Health Perspect. 2005, 113, 201-206.

25. Forbes, L.; Patel, M.; Rudnicka, A.; Cook, D.; Bush, T.; Stedman, J.; Whincup, P.; Strachan, D.; Anderson, H. Chronic exposure to outdoor air pollution and diagnosed cardiovascular disease: meta-analysis of three large cross-sectional surveys. Environ. Health 2009, 8, 30.

26. Grazuleviciene, R.; Maroziene, L.; Dulskiene, V.; Malinauskiene, V.; Azaraviciene, A.; Laurinaviciene, D.; Jankauskiene, K. Exposure to urban nitrogen dioxide pollution and the risk of myocardial infarction. Scand. J. Work Environ. Health 2004, 30, 293-298.

27. Orru, H.; Kaasik, M.; Antov, D.; Forsberg, B. Evolution of traffic flows and traffic-induced air pollution due to structural changes and development during 1993-2006 in Tartu (Estonia). Balt. J. Road. Bridge. Eng. 2008, 3, 206-212.

28. Hazenkamp-Von Arx, M.E.; Gotschi, T.; Ackermann-Liebrich, U.; Bono, R.; Burney, P.; Cyrys, J.; Jarvis, D.; Lillienberg, L.; Luczynska, C.; Maldonado, J.A.; Jaen, A.; de Marco, R.; Mi, Y.H.; Modig, L.; Bayer-Oglesby, L.; Payo, F.; Soon, A.; Sunyer, J.; Villani, S.; Weyler, J.; Kunzli, N. PM2.5 and $\mathrm{NO}_{2}$ assessment in 21 European study centres of ECRHS II: annual means and seasonal differences. Atmos. Environ. 2004, 38, 1943-1953.

29. Orru, H.; Kimmel, V.; Forsberg, B.; Soon, A. Elemental Composition and Oxidative Properties of PM2.5 in Relation of Origin of Air Masses in ERCHS II City Tartu, In 20th Annual Conference of the International-Society-for-Environmental-Epidemiology, Pasadena, CA, USA, Oct, 12-16, 2008; Lippincott Williams \& Wilkins: Pasadena, CA, USA, 2008; pp. S226-S226.

30. Turner, D.B. A diffusion model for an urban area. J. Appl. Meteorol. 1964, 3, 83-91.

31. Kaasik, M.; Kimmel, V. Validation of the improved AEROPOL model against the Copenhagen data set. Int. J. Environ. Pollut. 2003, 20, 114-120. 
32. Carruthers, D.J.; Holroyd, R.J.; Gunt, J.C.R.; Weng, W.-S.; Robins, A.G.; Apsley, D.D.; Thomson, D.J.; Smith, F.B. UK-ADMS: a new approach to modelling dispersion in the Earth's atmospheric boundary layer. J. Wind Eng. Ind. Aerodyn. 1994, 52, 139-153.

33. Cimorelli, A.J.; Perry, S.G.; Venkatram, A.; Weil, J.C.; Paine, R.J.; Wilson, R.B.; Lee, R.F.; Peters, W.D.; Brode, R.W. AERMOD: A dispersion model for industrial source applications. Part I: General model formulation and boundary layer characterization. J. Appl. Meteorol. 2005, 44, 682-693.

34. Kaasik, M.; Lukk, T.; Kartau, K.; Dovnar, T. Nowcasting and forecasting the street pollution dispersion for Tallinn metropolitan area 2007. In Developments in Environmental Science; Borrego, C., Renner, E., Eds.; Elsevier: Oxford, UK, 2007; Vol. 6, pp. 744-746.

35. Kimmel, V.; Kaasik, M. Assessment of Urban Air Quality in South Estonia by Simple Measures. Environ. Model. Assess. 2003, 8, 47-53.

36. Sofiev, M.; Kaasik, M.; Hongisto, M. Model Simulations of the Alkaline Dust Distribution from Estonian Sources over the Baltic Sea Basin. Water Air Soil Pollut. 2003, 146, 211-223.

37. Härkönen, J.; Nikmo, J.; Karppinen, A.; Kukkonen, J., A refined modelling system for estimating the emissions, dispersion, chemical transformation and dry deposition of traffic-originated pollution from a road. In A Refined Modelling System for Estimating the Emissions, Dispersion, Chemical Transformation and Dry Deposition of Traffic-Originated Pollution from a Road, Cuvelier, C., Ed. European Joint Research Centre: Belgirate, Italy, 2001; pp. 311-313.

38. Eneroth, K.; Johansson, C.; Bellander, T. Exposure Comparison between Measurements and Calculations Based on Dispersion Modelling; Stockholms och Uppsala Läns Luftvårsförbund: Stockholm, Sweden, 2006; p. 23.

39. Gerlofs-Nijland, M.E.; Dormans, J.; Bloemen, H.J.T.; Leseman, D.; Boere, A.J.F.; Kelly, F.J.; Mudway, I.S.; Jimenez, A.A.; Donaldson, K.; Guastadisegni, C.; Janssen, N.A.H.; Brunekreef, B.; Sandstrom, T.; Cassee, F.R. Toxicity of coarse and fine particulate matter from sites with contrasting traffic profiles. Inhal. Toxicol. 2007, 19, 1055-1069.

40. Schwarze, P.E.; Ovrevik, J.; Lag, M.; Refsnes, M.; Nafstad, P.; Hetland, R.B.; Dybing, E. Particulate matter properties and health effects: consistency of epidemiological and toxicological studies. Human Exp. Toxicol. 2006, 25, 559-579.

41. Valavanidis, A.; Fiotakis, K.; Vlachogianni, T. Airborne particulate matter and human health: toxicological assessment and importance of size and composition of particles for oxidative damage and carcinogenic mechanisms. J. Environ. Sci. Health C Environ. Carcinog. Ecotoxicol. Rev. 2008, 26, 339-362.

42. Wichmann, H.E. Diesel exhaust particles. Inhal. Toxicol. 2007, 1, 241-244.

43. Kafoury, R.; Madden, M. Diesel exhaust particles induce the over expression of tumor necrosis factor-ÎI (TNF-ÎI \pm ) gene in alveolar macrophages and failed to induce apoptosis through activation of nuclear factor- $\hat{I}^{\circ} \mathrm{B}$ (NF- $\left.\hat{I}^{\circ} \mathrm{B}\right)$. IJERPH 2005, 2, 107-113.

44. de Marco, R.; Cerveri, I.; Bugiani, M.; Ferrari, M.; Verlato, G. An undetected burden of asthma in Italy: the relationship between clinical and epidemiological diagnosis of asthma. Eur. Resp. J. 1998, 11, 599-605. 
45. Wilhelmsen, L.; Rosengren, A.; Hagman, M.; Lappas, G. "Nonspecific" chest pain associated with high long-term mortality: results from the primary prevention study in Goteborg, Sweden. Clin. Cardiol. 1998, 21, 477-482.

46. Lampe, F.C.; Whincup, P.H.; Wannamethee, S.G.; Ebrahim, S.; Walker, M.; Shaper, A.G. Chest pain on questionnaire and prediction of major ischaemic heart disease events in men. Eur. Heart J. 1998, 19, 63-73.

47. Walker, M.K.; Whincup, P.H.; Shaper, A.G.; Lennon, L.T.; Thomson, A.G. Validation of patient recall of doctor-diagnosed heart attack and stroke: A postal questionnaire and record review comparison. Am. J. Epidemiol. 1998, 148, 355-361.

48. Meisinger, C.; Schuler, A.; Lowel, H.; Grp, M.K. Postal questionnaires identified hospitalizations for self-reported acute myocardial infarction. J. Clin. Epidemiol. 2004, 57, 989-992.

49. Psaty, B.M.; Kuller, L.H.; Bild, D.; Burke, G.L.; Kittner, S.J.; Mittelmark, M.; Price, T.R.; Rautaharju, P.M.; Robbins, J. Methods of assessing prevalent cardiovascular disease in the Cardiovascular Health Study. Ann. Epidemiol. 1995, 5, 270-277.

50. Olsson, L.; Svardsudd, K.; Nilsson, G.; Ringqvist, I.; Tibblin, G. Validity of a postal questionnaire with regard to the prevalence of myocardial-infarction in a general-population sample. Eur. Heart J. 1989, 10, 1011-1016.

51. Rosenlund, M.; Bellander, T.; Nordquist, T.; Alfredsson, L. Traffic-generated air pollution and myocardial infarction. Epidemiology 2009, 20, 265-271.

52. Hoffmann, B.; Moebus, S.; Mohlenkamp, S.; Stang, A.; Lehmann, N.; Dragano, N.; Schmermund, A.; Memmesheimer, M.; Mann, K.; Erbel, R.; Jockel, K.H.; Heinz Nixdorf Recall, S. Residential exposure to traffic is associated with coronary atherosclerosis. Circulation 2007, 116, 489-496.

53. Babisch, W. Transportation noise and cardiovascular risk: updated review and synthesis of epidemiological studies indicate that the evidence has increased. Noise Health 2006, 8, 1-29.

54. Schwela, D.; Kephalopoulos, S.; Prasher, D. Confounding or aggravating factors in noise-induced health effects: air pollutants and other stressors. Noise Health 2005, 7, 41-50.

55. Allen, R.W.; Davies, H.; Cohen, M.A.; Mallach, G.; Kaufman, J.D.; Adar, S.D. The spatial relationship between traffic-generated air pollution and noise in 2 US cities. Environ. Res. 2009, 109, 334-342.

(C) 2009 by the authors; licensee Molecular Diversity Preservation International, Basel, Switzerland. This article is an open-access article distributed under the terms and conditions of the Creative Commons Attribution license (http://creativecommons.org/licenses/by/3.0/). 